\title{
De quem é o SUS? Sobre as representações sociais dos usuários do Programa Saúde da Família
}

\author{
Whose is SUS? About the social representation \\ of the users of the Family Health Program
}

Poliana Cardoso Martins ${ }^{1}$

Rosângela Minardi Mitre Cotta ${ }^{2}$

Fábio Farias Mendes ${ }^{2}$

Silvia Eloiza Priore ${ }^{2}$

Sylvia do Carmo Castro Franceschinni ${ }^{2}$

Mariana de Melo Cazal ${ }^{1}$

Rodrigo Siqueira Batista ${ }^{2}$

${ }^{1}$ Instituto Multidisciplinar em Saúde, Universidade Federal da Bahia. Instituto Multidisciplinar em Saúde. Rua Rio de Contas 58, quadra 17 , lote 58 , Candeias. 45029-094

Vitória da Conquista BA. poliana.martins@ufba.br

${ }^{2}$ Universidade Federal de Viçosa.

\begin{abstract}
The present study analyzes the representation of the users of SUS and PSF, presenting data obtained by semi-structured interviews, using the theoretical referential of the qualitative research. The results show a social representation marked by a focused vision and assistance, pointing to the concentration of public resources in poor segments of the society and centered in the biomedical model of attention. It stands out that PSF did not reach their objectives to provide changes in the praxis in health. In relation to the social control, it is observed that only $5.9 \%$ of the interviewees know the CMS. The presented data show a great ignorance by the studied population on the sanitary system and conquered social laws, and many people still see SUS as a "health plan for the poor". Due to the lived reality, the need of the implementation of strategies is emphasized for the reach of larger powerment/liberation of the population, seeking to build effective possibilities so that their actors will be active participant of the process of construction of a common project, actually based on the democratic ideals of SUS, being PSF strategically important in the accomplishment of these actions.
\end{abstract}

Key words Family Health Program, Social representation, Empowerment, Freedom, Democracy
Resumo O presente estudo analisa a representação social dos usuários sobre o SUS e o PSF, apresentando dados obtidos por intermédio de entrevistas semiestruturadas, utilizando o referencial teórico da pesquisa qualitativa. Os resultados mostram uma representação social marcada por uma visão focalizada e assistencialista, apontando para a concentração de recursos públicos em segmentos mais pobres da sociedade e centrada no modelo de atenção biomédico. Destaca-se que o PSF não conseguiu alcançar seus objetivos de proporcionar mudanças na práxis em saúde. Em relação ao controle social, observa-se que apenas 5,9\% dos entrevistados conhecem o CMS. Os dados apresentados mostram um grande desconhecimento da população estudada sobre o sistema sanitário e os direitos sociais conquistados, sendo que para muitos o SUS ainda é visto como um "plano de saúde para os pobres". Diante da realidade vivenciada, ressaltase a necessidade da implementação de estratégias para o alcance de maior empoderamento/libertação da população, visando construir possibilidades efetivas para que seus atores sejam participantes ativos do processo de construção de um projeto comum, realmente fundamentado nos ideais democráticos do SUS, sendo o PSF estrategicamente importante na realização dessas ações.

Palavras-chave Programa Saúde da Família, Representação social, Empoderamento, Libertação, Democracia 


\section{Introdução}

O Sistema Único de Saúde (SUS) surge como resultado da grande luta pela democratização da saúde no Brasil ${ }^{1}$, buscando a ampliação da organização popular, a universalização do acesso e o reconhecimento da saúde como direito universal do ser humano ${ }^{2}$. Assim, a criação do SUS abre perspectivas para apoiar ações que possam remeter à questão social, prevendo a participação popular na gestão pública, seja ou não por via institucional, prevalecendo, a vontade da população sobre aquela de qualquer indivíduo ou grupo ${ }^{3}$.

Entretanto, para que isto aconteça, é necessária a existência de espaços que possibilitem o empoderamento/libertação dos cidadãos, no sentido de ampliar a inclusão social. O empoderamento (empowerment) pode ser entendido como a ampliação das possibilidades de controle, por um sujeito/população, dos aspectos significativos relacionados à sua própria existência, de acordo com a concepção do economista indiano Amartya Kumar Sen ${ }^{4,5}$. No entanto, pode-se afirmar que o conceito de libertação do pensador brasileiro Paulo Freire ${ }^{6,7}$ refere-se ao mesmo fenômeno expresso na palavra empoderamento, em que os aspectos de inclusão social e resgate da cidadania vão além da questão de redistribuição de poder, abrangendo a necessidade de práticas educativas que estimulem a participação livre e crítica dos cidadãos ${ }^{8}$. Em decorrência disto, neste estudo utilizar-se-á o binômio "empoderamento/libertação" como forma de ampliar o entendimento de se empoderar.

Diante desta realidade, o Programa Saúde da Família (PSF), estratégia adotada para a reestruturação do sistema sanitário brasileiro, deve trabalhar para construir possibilidades efetivas para que a população seja participante ativa do processo de construção de um projeto comum, comprometendo-se com a produção de sujeitos reflexivos autônomos e socialmente solidários, criando espaços e práticas democráticas na práxis da atenção sanitária ${ }^{9,10}$.

Neste contexto, a proximidade e o vínculo estabelecido entre os profissionais e a comunidade fazem com que o PSF seja capaz de conhecer a realidade sanitária e traduzi-la para uma linguagem acessível à sua comunidade, possibilitando a construção de metas e pactos visando à melhoria na qualidade de vida da população, permitindo que estes exerçam um papel ativo sobre a organização do sistema local de saúde ${ }^{11}$. De fato, o PSF deve ser entendido no contexto da participação social, através da lógica da vigilân- cia à saúde, representada pela concepção da saúde centrada na promoção da qualidade de vida ${ }^{12}$ e no usuário, através do modelo usuário-centrado, que coloca o cidadão no centro da atenção e do cuidado em saúde ${ }^{13}$.

Retomando a discussão sobre o fortalecimento do controle social no âmbito do SUS e a necessidade de cidadãos empoderados/libertos, com motivação e competência para avaliar e transformar a realidade vivida no seu próprio sistema sanitário, vale salientar que o envolvimento da população na tomada de decisão possibilita avançar na qualidade dos serviços e ações em saúde, na medida em que seus atores se tornam capazes de compreender a realidade vivida, apontar os problemas e as soluções relativas às suas reais necessidades ${ }^{10,14,15}$. Nesse sentido, a compreensão das representações sociais dos usuários sobre o SUS e sobre o PSF é objeto de interesse especial neste estudo.

Representações sociais são entidades quase tangíveis, que circulam, se entrecruzam e se cristalizam continuamente através de uma palavra, de uma ação ou de um gesto, podendo ser definidas como senso comum, imagens, concepções e visão de mundo que os atores sociais possuem sobre a realidade ${ }^{16,17}$. São modalidades de conhecimento prático orientadas para a comunicação e para a compreensão do contexto social, material e ideativo em que vivemos. Estas são socialmente elaboradas e compartilhadas, contribuindo para a construção de uma realidade comum, na qual o sujeito é responsável pela construção dessa realidade como um sujeito social. Assim, as representações são sempre construções contextualizadas ${ }^{18}$.

Com a intenção de aprofundar e enriquecer o debate sobre a temática do processo de construção do SUS e a participação dos cidadãos nessas ações, este artigo tem como objetivo analisar as representações sociais do SUS e do PSF pelos usuários efetivos deste sistema sanitário. Esta análise possibilitará a compreensão de como tais representações são produzidas, atualizadas ou transformadas e, consequentemente, como podem contribuir para o planejamento de ações que possibilitem o desenvolvimento de estratégias de empoderamento/libertação da população e a transformação desses importantes atores sociais no processo de formulação de políticas de saúde no âmbito municipal.

O estudo aqui apresentado faz parte da dissertação de mestrado Controle social no Sistema Único de Saúde: análise da participação social e do empoderamento da população no município de 
Teixeiras, $M G$ (Universidade Federal de Viçosa), financiada pela Fapemig EDT.

\section{Metodologia}

Este estudo situa-se no campo da pesquisa social e utiliza, primordialmente, o referencial teórico metodológico instrumental da pesquisa qualitativa ${ }^{16,19}$.

Ao assumir a hipótese norteadora de que a consciência social para a concretização do direito à saúde só se dá pela construção da cidadania, pelo consequente empoderamento/libertação da população usuária do sistema e pela criação de espaços públicos que permitam tais ações, direcionou-se a investigação para uma abordagem social qualitativa e quantitativa, possibilitando assim medir os processos e, ao mesmo tempo, compreender e interpretar como os atores se entrelaçam em seu contexto social. Esta estratégia metodológica é conhecida como triangulação de métodos ${ }^{19}$.

Essa estratégia foi utilizada para a análise das representações sociais dos atores entrevistados sobre o SUS e o PSF, na tentativa de absorver a representação particular desse processo de construção social a respeito de um sistema sanitário socialmente valorizado de acordo com a posição da sociedade e seus interesses específicos, trazendo à tona a emoção, o entendimento e o sentimento que os sujeitos sociais dão à sua realidade.

\section{Descrição do universo estudado}

A pesquisa foi realizada no período de abril a setembro de 2006, no município de Teixeiras, localizado na Zona da Mata de Minas Gerais. Este município apresentou no ano de 2000 uma população de 11.149 habitantes. Segundo dados do mesmo censo, a maioria dos municípios brasileiros (90,47\%) é considerada de pequeno porte, cuja população é de até 50.000 habitantes ${ }^{20}$.

No que se refere às condições socioeconômicas, a taxa de analfabetismo é de $17 \%$ na população adulta com mais de 25 anos; a economia se baseia na agricultura; e a renda per capita média é de $\mathrm{R} \$ 171,89^{21}$.

Em relação á cobertura do PSF, observa-se que 94,82\% da população é atendida, sendo que funcionam no município, ao todo, quatro equipes ${ }^{9}$.

Diante desses dados, acredita-se que a realidade estudada possa ser extrapolada para muitos municípios brasileiros que apresentam características socioeconômicas e demográficas semelhantes ao universo estudado. Desta forma, espera-se que os resultados aqui apresentados possam contribuir para o trabalho de diversos profissionais, gestores e pesquisadores que lidam com cotidiano do SUS em todo o país.

\section{Atores sociais estudados}

Dada a dificuldade encontrada em se delimitar o todo representado pela amostra ${ }^{22}$, uma vez que os usuários do PSF nem sempre são um conjunto homogêneo, optou-se por entrevistar os usuários que frequentam as atividades desenvolvidas pelo Programa de Atenção à Hipertensão Arterial e ao Diabetes Mellitus (Hiperdia). Acredita-se que estes, por serem usuários efetivos do PSF (longitudinalidade da atenção), estão mais capacitados para avaliar de forma expressiva a realidade das ações desenvolvidas. Da mesma forma, espera-se que tais usuários apresentem um conhecimento ímpar sobre o SUS e o PSF, uma vez que eles frequentam a unidade de saúde no mínimo duas vezes por ano, isto é, são agendadas consultas no mínimo de seis em seis meses, além da possibilidade de participarem de atividades educativas desenvolvidas pela equipe ${ }^{23}$.

Nesse sentido, o grupo em estudo foi de 136 usuários do PSF (11\% dos cadastrados no Hiperdia e que realizavam acompanhamento nas quatro unidades), selecionados de forma aleatória durante os atendimentos e atividades realizadas pelas equipes.

\section{Coleta e análise dos dados}

Os dados foram coletados por meio de entrevistas semiestruturadas. O método adotado para compreensão dos dados foi a "análise de conteúdo", que consiste em descobrir os núcleos de sentido que compõem o grupo estudado e cuja presença ou frequência de aparição pode ser relevante segundo o objetivo do estudo ${ }^{24}$. De acordo com $\operatorname{Bardin}^{24}$, a análise de conteúdo é a técnica de análise das comunicações visando obter, por procedimentos sistemáticos e objetivos de descrição do conteúdo das mensagens, indicadores (qualitativos ou não) que permitam a inferência de conhecimentos relativos às condições de produção/recepção dessas mensagens.

Destacamos que, na apresentação das falas transcritas, foram respeitadas a grafia e a sintaxe utilizadas pelos entrevistados. Objetivando preservar a identidade dos mesmos, foram colocados no final das falas os números dos questionários.

Respeitando os aspectos éticos, conforme a Resolução no 196/96 do Conselho Nacional de 
Saúde, o projeto de pesquisa foi submetido ao Comitê de Ética em Pesquisa com Seres Humanos da Universidade Federal de Viçosa e todos os entrevistados assinaram o Termo de Consentimento Livre Esclarecido.

\section{Resultados}

\section{Perfil socioeconômico dos usuários}

Alguns indicadores quantitativos serão brevemente apresentados, visando descrever o perfil socioeconômico do grupo estudado. Entre os 136 entrevistados, a idade variou de 28 a 85 anos, sendo que a idade média encontrada foi de 60 anos $( \pm 10,59)$ e $53,7 \%$ do total apresentaram 60 anos ou mais. Houve predomínio do sexo feminino $(77,9 \%)$. Destaca-se que $42,6 \%$ dos atores entrevistados não tinham renda fixa, 44,9\% eram aposentados ou pensionistas e apenas $12,5 \%$ tinham emprego formal. A renda familiar mediana foi de $\mathrm{R} \$ 450,00$ (mínimo de R \$ 100,00 e máximo de R \$ $3.500,00$ ), sendo que $54,4 \%$ dos entrevistados apresentaram renda per capita inferior ou igual a $1 / 2$ salário mínimo, considerados assim como situados abaixo da linha da pobreza ${ }^{21}$. As profissões que mais se destacaram foram: donas de casa
$(45 \%)$ e trabalhadores rurais $(32,4 \%)$. Quanto à escolaridade, $86 \%$ dos entrevistados tinham quatro anos ou menos de estudo.

\section{Representações sociais dos usuários sobre o Sistema Único de Saúde}

$\mathrm{Na}$ Figura 1, podem ser observadas as representações sociais dos usuários entrevistados sobre o SUS. Deve-se pontuar, entretanto, que 14,6\% destes não souberam descrever de forma espontânea o que significava para eles o SUS. Diante da realidade encontrada no universo em estudo, tem-se que as diferentes noções e representações sociais sobre o SUS compõem um espaço global, em que coexistem quatro subespaços que representam as principais características discursivas dos usuários. Nestes subespaços se produziram e condensaram diferentes noções sobre o SUS.

No eixo y, apresenta-se na parte superior visões positivas sobre o SUS, e na parte inferior, visões negativas. Nota-se que $48,5 \%$ dos discursos tiveram conotações positivas em relação ao SUS, como por exemplo o fato de receber atendimentos gratuitos, e apenas $9,6 \%$ tinham a concepção do SUS como um sistema de saúde universal. Entre os entrevistados que apresentavam visões negativas do SUS, destaca-se o predomí-



Figura 1. Subespaços construídos a partir das representações sociais do Sistema Único de Saúde dos usuários do PSF, município de Teixeiras (MG) - 2006.

Fonte: adaptado e modificado de Conde \& Concha $^{25}$. 
nio de representações deste como um "plano de saúde para pobres" $(19,1 \%)$.

No eixo x apresentam-se percepções sobre focalização e universalização do SUS. Observase, então, que o olhar do usuário sobre o SUS ainda é bastante centrado na focalização, principalmente no que se refere à realização de procedimentos assistenciais, como consultas $(48,5 \%)$, e ao fato de o SUS ser representado como um "plano de saúde para os pobres" (19,1\%). A seguir serão descritas algumas falas que ilustram a representação por parte dos entrevistados de um SUS focalizado:

Eu sou pobre [...] isso pra mim é uma dádiva de Deus, eu venho aqui e sou muito bem atendido, faço minhas consultas, pode até demorar um pouco às vezes, mas é bom demais, afinal de contas eu não pago nada... (51)

É uma coisa boa demais para os pobres fazerem consultas e receberem remédios. (20)

Um aspecto importante a ser ressaltado no estudo é que apesar de todos os entrevistados serem usuários do PSF, 23,5\% afirmaram que não utilizavam o SUS, o que traduz também um desconhecimento sobre o sistema sanitário.

Em relação à qualidade, 71,3\% dos entrevistados consideram o SUS como ótimo ou bom, e entre estes, 92\% identificam o SUS como um local de atendimento e/ou um "plano de saúde para os pobres".

\section{Representações sociais dos usuários sobre o Programa Saúde da Família}

As representações do PSF foram semelhantes à do SUS, em que o PSF para 64\% dos entrevistados foi representado como um local para a realização de consultas, controle e continuidade do tratamento, conceitos ainda muito centrados no modelo biomédico da assistência (Tabela 1).

A seguir são apresentadas algumas falas dos usuários que ilustram a situação descrita:

Para mim o PSF é como se fosse um hospital onde fazemos as consultas, deixando o antigo hospital só para as emergências. (8)

Nossa, aqui é o lugar onde consegui controlar minha pressão e a glicose [...] aí venho de $3 \mathrm{em} 3$ meses, porque aprendi que assim é melhor pra minha saúde. (49)

Um ponto curioso a se destacar é que 1,5\% dos entrevistados associaram o PSF à sigla de partidos políticos: Eu não gosto de me meter em politica, você sabe como é cidade pequena, esse negócio de PFL e PT só dá confusão, nem consigo entender isso... (88), em que o entrevistado confunde a sigla do PSF com a do Partido da Frente Liberal (PFL).

Vale ressaltar que 16,8\% dos usuários identificam a importância do PSF no processo de reestruturação do sistema sanitário brasileiro, em que esta estratégia passa a representar a porta de entrada do sistema sanitário e uma mudança na práxis em saúde, fortalecendo o vínculo entre a população e a equipe, privilegiando ações de promoção da saúde e prevenção de doenças, representando um modelo de atenção à saúde centrado no usuário e em suas necessidades, conforme pode ser identificado nas falas destacadas a seguir:

É o programa que trouxe maior acesso da população aos serviços de saúde. Também trouxe mais informação, maior cuidado com a saúde e até diversão para o povo. Você sabe que aqui temos o forró da terceira idade? (3)

É como se fosse uma família que cuida da nossa saúde. Aqui eu me sinto muito à vontade, sei que todo mundo me conhece e se preocupa comigo. (33)

Tabela 1. Núcleos de sentido sobre o PSF, conforme o relato dos usuários do Hiperdia do município de Teixeiras (MG) - 2006.

\begin{tabular}{|c|c|c|c|c|c|c|c|}
\hline \multicolumn{8}{|c|}{ Representação dos usuários sobre o Programa Saúde da Família } \\
\hline \multicolumn{2}{|c|}{ Modelo usuário-centrado } & \multicolumn{2}{|l|}{ Modelo biomédico } & \multicolumn{2}{|c|}{ Programa focalizado } & \multicolumn{2}{|c|}{ Desconhecimento } \\
\hline Conceito & $\%$ & Conceito & $\%$ & Conceito & $\%$ & Conceito & $\%$ \\
\hline $\begin{array}{l}\text { Porta de entrada do } \\
\text { SUS/ mudança no } \\
\text { foco da atenção }\end{array}$ & 8,8 & $\begin{array}{l}\text { Local que possibilita } \\
\text { realização de consultas, } \\
\text { controle e continuidade } \\
\text { do tratamento }\end{array}$ & 64,0 & $\begin{array}{l}\text { Plano de } \\
\text { saúde para } \\
\text { pobres }\end{array}$ & 4,4 & $\begin{array}{l}\text { Não sabe } \\
\text { definir }\end{array}$ & 10,3 \\
\hline $\begin{array}{l}\text { Possibilita maior } \\
\text { vínculo entre a } \\
\text { população e a equipe }\end{array}$ & 8,0 & $\begin{array}{l}\text { Local que possibilita } \\
\text { prevenção de doenças }\end{array}$ & 2,3 & $\begin{array}{l}\text { Atende a } \\
\text { zona rural }\end{array}$ & 0,7 & $\begin{array}{l}\text { Partido } \\
\text { político }\end{array}$ & 1,5 \\
\hline
\end{tabular}


Espera-se que o PSF funcione como um instrumento para o empoderamento/libertação dos usuários, transformando-os em sujeitos sociais ativos no processo de construção de um projeto assistencial comum. Tendo como referência esta perspectiva, perguntamos aos entrevistados se eles identificavam no PSF algum mecanismo que os estimulassem a participar (como usuários) das ações, atividades e serviços de saúde oferecidos à sua família e à comunidade onde vivem, favorecendo assim o controle (como sujeito) sobre as ações e decisões que afetam a sua saúde. Os resultados demonstram que $86,8 \%$ dos entrevistados acreditam que o PSF estimula sua participação nas atividades desenvolvidas. Entretanto, a grande maioria justifica que a maior participação nas atividades do programa está ligada apenas ao fato do agendamento prévio das consultas pelos agentes comunitários de saúde (ACS), facilitando assim seu acesso aos atendimentos prestados pelos médicos. Destacamos que nenhum entrevistado mencionou a possibilidade de participar como um ator ativo na formulação de políticas e ações de saúde ligadas à comunidade onde vive. Já em relação à ampliação do controle sobre as decisões e ações que afetam sua saúde, 72,8\% afirmam terem se tornado sujeitos mais ativos em relação à sua saúde. Todos informaram que mudaram sua conduta individual e passaram a controlar a dieta, os medicamentos, praticar atividade física e frequentar mais as consultas, o que pode ser visualizado por meio das falas destacadas a seguir:

Agora com o PSF é mais fácil de participar, eles marcam as consultas, eu nem preciso mais vir pegar ficha aqui. (11)

Com o doutor eu aprendi a controlar aquelas coisas que podem atrapalhar minha saúde, antes eu nem pensava nisso. Eu tomo remédio, faço caminhada e mudei um pouco a alimentação. (48)

Não obstante, os dados deste estudo apontam para o fato de o PSF favorecer apenas o empoderamento individual dos usuários, uma vez que eles relatam mudanças em atitudes pessoais que poderiam causar danos à sua saúde. Vale ressaltar que questões relacionadas à libertação dos cidadãos visando à sua inclusão social - compreendendo o empoderamento/libertação como a ampliação das possibilidades de controle dos aspectos significativos relacionados à sua própria existência, constituindo uma excelente alternativa para a redução dos aspectos de inclusão social e resgate da cidadania - não apareceram nos relatos dos entrevistados.

\section{Conselhos Municipais de Saúde: o desconhecimento da população desse espaço institucionalizado para o exercício do controle social}

No contexto da participação do usuário no SUS, os conselhos e as conferências de saúde são considerados como os espaços legalmente instituídos para tal fim. Dentre os entrevistados, apenas $5,9 \%$ tinham conhecimento sobre o Conselho Municipal de Saúde (CMS) e sabiam o seu significado, mesmo que de forma incompleta, como pode ser observado nos relatos a seguir:

...reunião de pessoas independentes para discutir questões de saúde; infelizmente entram questões políticas no meio. (75)

...é o povo unido para mudar a saúde. (133)

Quando os entrevistados não conheciam a função do CMS, esclarecíamos sobre o papel do conselho e perguntávamos se eles teriam vontade de participar das reuniões. Assim, 53,7\% dos usuários entrevistados afirmaram que gostariam de participar e $17,6 \%$ disseram que talvez participassem das reuniões, sendo que a falta de tempo foi o principal obstáculo para a participação.

Não obstante, 89,7\% dos usuários julgavam importante a participação da população na tomada de decisões sobre as ações de saúde do município. Destes, 54,9\% acreditavam que as reuniões do CMS poderiam representar uma boa oportunidade para que a população conhecesse mais sobre o funcionamento do setor saúde no município; $24,9 \%$ acreditavam que o povo seria capaz de auxiliar o gestor municipal na tomada de decisão em saúde; $15,9 \%$ achavam que o povo é o principal interessado e realmente deve participar das reuniões; e $4,4 \%$ pensavam que realmente seria importante a participação da população nessas reuniões, entretanto não acreditam na possibilidade concreta de os políticos permitirem a participação da população, conforme pode ser observado na fala destacada a seguir:

O povo deve participar, este é um princípio da democracia, infelizmente no Brasil não temos uma verdadeira democracia, pois os políticos nos são impostos e não existe espaços para participar; na verdade eles não querem que o povo participe, preferem que continuem todos alienados. (75)

\section{Discussão}

Ao avaliar de forma global os dados encontrados, observa-se que a representação social dos 
usuários referente ao SUS encontra-se ainda marcada por uma visão focalizada e assistencialista da atenção à saúde, destacando a concentração dos recursos públicos na realização de procedimentos menos complexos e no atendimento dos segmentos mais pobres e excluídos da sociedade. Essa visão pode estar associada ao desconhecimento da sociedade de seu sistema sanitário, uma vez que, para muitos, saúde não é vista como um direito do cidadão, retratando assim a falta de tradição do povo brasileiro no exercício da cidadania ${ }^{26}$, deixando de lado a possibilidade de atuar como protagonista na construção e no aprimoramento do sistema.

Pode-se identificar uma realidade semelhante na análise dos dados do levantamento realizado pelo Conselho Nacional de Secretários de Saúde (Conass), segundo o qual apenas 35\% dos cidadãos entrevistados souberam citar, espontaneamente, com precisão, o que significa "SUS", sendo que mais de 55\% admitiram não conhecer o significado ${ }^{27}$.

Mesmo diante do desconhecimento dos usuários, não se pode deixar de destacar o notório avanço legal representado pela criação do SUS no Brasil, principalmente quando se pensa nos direitos sociais conquistados pela população. Entretanto, é igualmente importante destacar que a instituição desse sistema se deu numa época em que a população ainda carregava as marcas de um contexto autoritário, repressor e de baixa percepção política ${ }^{28,29}$. Assim, o resultado da implantação desta política no Brasil ainda não foi consagrado por toda a população, uma vez que grande parte dos cidadãos ainda se situa à margem da comunidade política, o que certamente tem implicações em nosso padrão de intervenção pública e participação social.

A visão focalizada do SUS representada pela população usuária entrevistada é o retrato da prática de implantação do sistema sanitário, segundo a qual este foi alvo das tensões provocadas pelas "externalidades" advindas dos ajustes econômicos e políticas neoliberais no Brasil, que geraram tensões e conflitos entre os distintos atores envolvidos na área da saúde ${ }^{30}$.

A realidade vivenciada na implantação do SUS levou a uma "universalização excludente", ou seja, juntamente com o acesso aos serviços de saúde a toda a população, independentemente da sua posição no mercado formal de trabalho - ao menos assim está escrito na lei -, ocorreu a precarização desses serviços, resultando na exclusão das camadas mais bem remuneradas da sociedade para o sistema privado ${ }^{31,32}$.
De forma mais ampla, o que ocorreu no Brasil foi a combinação entre focalização e universalização, configurando perigosamente a focalização como uma estratégia de implantação da universalização. Assim, na década de 90 é formulado e implantado o PSF, vislumbrando a mudança do modelo de atenção à saúde vigente no país ${ }^{33}$. Desta forma, o PSF oriundo de uma exigência de mercado é transformado em um instrumento para se garantir a universalidade de acesso aos serviços de saúde da população ${ }^{34}$, mesmo que num primeiro momento apenas as classes mais excluídas da sociedade tenham maior contato com esta estratégia.

Neste momento, se faz necessário levantar um grande problema do SUS, que é a necessidade de garantir um mínimo básico, e hierarquizar o sistema, assegurando a atenção integral - de promoção, prevenção e cura. A realidade que se observa é de uma tendência à especialização do SUS em tecnologias de cuidados de baixa complexidade, como as da atenção básica ${ }^{35}$, às quais vem paulatinamente se somando uma rede pública de hospitais de pequeno porte e baixo grau de complexidade, enquanto o setor privado, mais dinâmico, passa a priorizar os segmentos de atenção de média e alta complexidade mais bem remunerados pela tabela SUS e mais valorizados e utilizados por compradores de planos de saúde priva$\operatorname{dos}^{32,36}$. Assim, temos um SUS pobre para os pobres e um SUS rico para os ricos e médios-altos.

Outro ponto importante de se destacar é que grande parte das representações dos entrevistados ainda apresenta conotações fortemente centradas no modelo biomédico de atenção, não absorvendo assim a ideia da mudança na práxis em saúde trazida pela implantação do PSF em todo o país; para muitos, o PSF continua a ser o "posto de saúde”. Segundo Merhy ${ }^{37}$, um dos grandes desafios para a mudança do paradigma sanitário refere-se à possibilidade de se atuar em um terreno de políticas e organizações, fortemente instituído pela presença de forças políticas hegemônicas e coorporativas muito bem estruturadas histórica e socialmente, como no caso dos modelos médicos e sanitários de intervenção em saúde.

Ao assumir a mudança no paradigma assistencial, passando de um eixo curativo para o preventivo e que visa à promoção da saúde, da ação monossetorial para a intersetorial e da exclusão para a universalidade, o PSF pode se tornar um instrumento-chave para o empoderamento/libertação da população, fato este evidenciado ainda de forma incipiente no presente estudo.

Para Bossi e Mercado $^{38}$, faltam à população questões que vão além da necessidade de um di- 
agnóstico do que é direito dos cidadãos em saúde; é preciso que se tenham reivindicações, ou seja, que os usuários acreditem na possibilidade de transformação da realidade vivida. Diante dessa realidade, o PSF pode assumir uma função primordial na transformação da sociedade, uma vez que pode possibilitar aos indivíduos e à coletividade o desenvolvimento de competências para participar da vida em sociedade, incluindo habilidades e pensamentos reflexivos, saindo assim de uma situação de resignação e acomodação em relação à realidade vivida.

Esta questão nos remete à discussão sobre por que alguns indivíduos acabam por não reivindicarem os seus direitos; desta forma tomamos emprestadas as palavras de Amartya Sen ${ }^{4}$, para descrever a situação de resignação na qual a população pode se encontrar em determinados momentos de seu cotidiano: Os fracassados e os oprimidos acabam por perder a coragem de desejar coisas que outros, mais favoravelmente tratados pela sociedade, desejam confiantemente.

Num contexto em que as desigualdades e privações estão arraigadas, as pessoas não continuam lamentosas e pesarosas todo o tempo. $\mathrm{Na}$ verdade, iniciam um processo de realizar grandes esforços para conseguirem tirar prazer de pequenas dádivas oferecidas a elas, reduzindo assim seus desejos pessoais a modestas proporções de benefícios que lhes são oferecidos ${ }^{5}$.

Não obstante, a inserção de práticas que visem ao empoderamento/libertação do cidadão podem vir a reverter essa situação. Para o sucesso dessa proposta, se faz necessário que o cidadão passe a ser o centro do modelo de prestação de cuidados em saúde, implicando a necessidade de se criarem condições para que o cidadão tenha possibilidade de se expressar e transformar a realidade vivida, proporcionando assim uma nova distribuição de deveres e direitos entre o Estado e a sociedade, redimensionando a questão da participação, que passa a ser entendida como prérequisito institucional e político para a definição da "saúde que queremos". Esta não é apenas uma circunstância desejável, mas uma condição indispensável para a viabilidade e a efetividade das políticas públicas de saúde realmente fundamentadas nos princípios doutrinários do SUS ${ }^{39}$.

Esta abordagem trabalha a noção de poder como um recurso distribuído de forma desigual na sociedade ${ }^{40,41}$ e uma questão geradora de conflito, na qual convivem visões potencialmente criativas e transformadoras com elementos de conservação do status quo. Parte do paradigma de que a sociedade é constituída por diferentes gru- pos de interesse, com níveis diferenciados de poder e de controle sobre os recursos, fazendo com que processos de empoderamento levem à redistribuição de poder e à inclusão social/libertação ${ }^{7}$.

Assim, é interessante ressaltar a importância do desenvolvimento de práticas democráticas no processo de trabalho em saúde, na medida em que a participação não é um conteúdo que se possa transmitir, tampouco uma destreza que se possa adquirir pelo mero treinamento, mas uma mentalidade e um comportamento a ser construído pela reflexão crítica e pelo amadurecimento do cidadão. De fato, a participação é uma vivência coletiva e não individual, de modo que somente se pode aprender na práxis grupal e só se aprende a participar participando ${ }^{42}$. Os limites para o processo de participação não se dão apenas por falta de infraestrutura e recursos, mas pela falta de uma cultura de participação, uma cultura cívica, assim como uma falta de vontade política para que a cidadania de fato seja exercida. Para que se fomente a participação social, é essencial a acumulação de experiências bem-sucedidas de união e cooperação entre os cidadãos e o Estado que reforcem condutas de confiança recíproca ${ }^{43,44}$.

Finalmente, destaca-se o desconhecimento da existência do CMS por parte dos entrevistados. Esta situação já foi descrita na literatura como uma das principais questões que comprometem a atuação dos conselhos. Este desconhecimento é oriundo principalmente da não divulgação deles, representando como resultado final uma baixa adesão da população nos processos decisórios. Assim, vivencia-se uma realidade em que o CMS é uma instituição muito valorizada por aqueles que dele participam, mas desconhecido pelos demais cidadãos ${ }^{3,32}$.

\section{Considerações finais}

Diante da realidade vivenciada, tem-se que o SUS ainda é visto de forma focalizada por muitos dos usuários e distanciando-se do verdadeiro exercício da cidadania, idealizado com a criação desse novo modelo sanitário. Destarte, vale ressaltar a necessidade de que se criem possibilidades efetivas para que a população seja participante ativa do processo de construção de um projeto comum, fundamentado nos ideais democráticos do SUS, criando, desta forma, espaços de empoderamento/libertação dos usuários.

No campo da saúde pública, a participação popular se faz de extrema importância, devido 
ao fato de que só é possível alcançar a qualidade nos serviços e ações de saúde com a participação de uma coletividade capaz de apontar os problemas e as soluções relativas às suas demandas, permitindo o avanço na consolidação de um SUS verdadeiramente universal, humanizado e acolhedor, transcendendo a ideia corrente de um sistema focalizado que presta consultas gratuitas à população carente.

Mas, afinal, de quem é o SUS?

O SUS é de todos e de cada um dos cidadãos que vivem nos diferentes municípios brasileiros, afirmativa inscrita na própria história do sistema, na medida em que este nasceu de uma demanda do povo brasileiro por um país mais justo, solidário e equitativo, sendo, portanto, a expressão maior de uma política democrática e social. Resta, portanto, que cada um ocupe os espaços institucionais de participação, ou como diria João Cabral de Melo Neto, cantado por Chico Buarque, que cada um dos cidadãos brasileiros repense e tome posse da "parte que lhe cabe neste latifúndio".

\section{Colaboradores}

PC Martins foi a responsável pelo planejamento, execução das atividades de campo, redação e revisão do manuscrito; RMM Cotta, pela coordenação, planejamento, orientação metodológica, acompanhamento do trabalho de campo, redação e revisão do artigo; FF Mendes, SE Priore e SCC Franceschinni participaram do planejamento e auxiliaram na redação e revisão do manuscrito; MM Cazal trabalhou no planejamento e execução das atividades de campo e auxiliou na redação do manuscrito; RS Batista auxiliou na redação e na revisão do manuscrito.

\section{Referências}

1. Labra ME, Figueiredo JSA. Associativismo, participação e cultura cívica: o potencial dos Conselhos de Saúde. Cien Saude Colet 2002; 7(3):537-547.

2. Brasil. Ministério da Saúde. Conselho Nacional de Saúde. A prática do controle social: Conselhos de Saúde e financiamento do SUS. Brasília: Ministério da Saúde; 2002.

3. Labra ME. Conselhos de Saúde: dilemas, avanços e desafios. In: Lima NT, Gerschman S, Elder FC. Saúde e democracia. Rio de Janeiro: Editora Fiocruz; 2005.

4. Sen AK. ¿Por qué la equidade en salud? Pan American Journal of Public Health 2002; 11(5-6):302-309.

5. Sen AK. Desigualdade reexaminada. Rio de Janeiro: Record; 2001

6. Freire P. Pedagogia da autonomia: saberes necessários à prática educativa. São Paulo: Paz e Terra; 2003.

7. Freire P. Pedagogia do oprimido. $38^{\mathrm{a}}$ ed. São Paulo: Paz e Terra; 2004.

8. Garrafa V. A inclusão social no contexto da bioética. Conferência apresentada no Seminário mensal julho/2005 da Agência Nacional de Vigilância Sanitária (Anvisa), em Brasília (DF), e no painel "Bioética: inclusão e justiça social”, no VI Congresso Nacional da Rede Unida, Belo Horizonte; 2005.

9. Brasil. Ministério da Saúde. Departamento de Atenção Básica. [site da Internet] [acessado 2007 abr 10]. Disponível em: http://dab.saude.gov.br/ atencaobasica.php 
10. Cotta RMM, Schott M, Azeredo CM, Franceschini SCC, Priore SE, Dias G. Organização do trabalho e perfil dos profissionais do Programa Saúde da Família: um desafio na reestruturação da atenção básica em saúde. Rev Epidemiologia e Serviços de Saúde 2006; 15(Supl.3):7-18.

11. Oliveira JB, Gusmão SC. A experiência de Saúde da Família no estímulo à participação social no município de Vitória da Conquista (BA). In: Seclen-Palacin JA, Fernandes AS, organizadores. Experiências e desafios da atenção básica e saúde familiar: caso Brasil. Brasília: Organização Pan-Americana da Saúde; 2004. p. 63-76.

12. Mendes EV. Uma agenda para a saúde. SãoPaulo: Hucitec; 2006.

13. Ayres JRCM. Cuidado e reconstrução das práticas de saúde. Interface - Comunicação, Saúde e Comunicação set.2003-fev.2004; 8(14):73-92.

14. Andrade GRB, Vaitsman J. Apoio social e redes: conectando solidariedade e saúde. Cien Saude Colet 2002; 7(4):925-934.

15. Guizardi FL, Pinheiro R. Dilemas culturais, sociais e políticos da participação dos movimentos sociais nos Conselhos de Saúde. Cien Saude Colet 2006; 11(3):797-805.

16. Minayo MCS Pesquisa social: teoria, método e criatividade. $21^{\mathrm{a}}$ ed. Petrópolis: Vozes; 1994.

17. Moscovici S. Representações sociais: investigações em psicologia social. Petrópolis: Vozes; 2003.

18. Spink MJP. The concept of social representations in social psychology. Cad Saude Publica 1993; 9(3):300-308.

19. Minayo MCS. Avaliação por triangulação de métodos. Rio de Janeiro: Editora Fiocruz; 2005.

20. Instituto Brasileiro de Geografia e Estatística (IBGE). Censo Demográfico de 2000. (CD-ROM). Rio de Janeiro: IBGE; 2000.

21. Programa das Nações Unidas para o Desenvolvimento (PNUD), Instituto de Pesquisa Econômica Aplicada (Ipea), Fundação João Pinheiro (FJP). Atlas do Desenvolvimento Humano no Brasil: Índice de Desenvolvimento Humano Municipal. Brasília: PNUD, Ipea, FJP; 2003. [acessado 2007 abr 10]. Disponível em: http://www.ipea.gov.br/

22. Becker H. Métodos de pesquisa em ciências sociais. $4^{\text {a }}$ ed. São Paulo: Hucitec; 1999.

23. Brasil. Ministério da Saúde. Secretaria de Políticas de Saúde. Departamento de Ações Programáticas Estratégicas. Plano de reorganização da atenção à hipertensão arterial e ao diabetes mellitus: hipertensão arterial e diabetes mellitus. Brasília: Ministério da Saúde; 2001.

24. Bardin L. Análise de conteúdo. Lisboa: Edições 70; 1977.

25. Conde F, Concha G. La evolución de las representaciones sociales sobre la salud de las mujeres madrileñas - 1993-2000. Revista Española de Salud Pública 2002; 76:493-507.

26. Siqueira-Batista R. Miséria. $3^{\text {a }}$ ed. Rio de Janeiro: KroArts; 2007.

27. Brasil. Conselho Nacional de Secretários de Saúde. A saúde na opinião dos brasileiros. Brasília: Conass; 2003.
28. Magalhães MDB. A lógica da suspeição: sobre os aparelhos repressivos à época da ditadura militar no Brasil. Revista Brasileira de História 1997; 34(17):203-220.

29. Carvalho JM. A cidadania no Brasil. Rio de Janeiro: Civilização Brasileira; 2001.

30. Correia MVC. Desafios para o controle social: subsídios para a capacitação de conselheiros de saúde. Rio de Janeiro: Editora Fiocruz; 2005.

31. Faveret Filho P, Oliveira PJ. A universalização excludente: reflexões sobre as tendências do sistema de saúde. Dados - Revista de Ciências Sociais 1990; 33(2):257-283.

32. Cotta RMM, Mendes FF, Muniz JN. Descentralização das políticas públicas de saúde: do imaginário ao real. Viçosa: UFV/Cebes; 1998.

33. Almeida MI. Modalidade de conhecimento socialmente elaborado: atores sociais no Programa de Saúde da Família. Acta Scientiarum - Health Sciences 2003; 25(2):227-235.

34. Cohn A. O SUS e o direito à Saúde: universalização e focalização nas políticas de saúde. In: Lima NT, Gerschman S, Elder FC, organizadores. Saúde e democracia. Rio de Janeiro: Editora Fiocruz; 2005.

35. Bahia L. Planos privados de saúde: luzes e sombras no debate setorial dos anos 90. Cien Saude Colet 2001; 6(2):329-339.

36. Santos MAB, Gerschman S. Segmentations of health service supply in Brazil: institutional arrangements, creditors, payers and providers. Cien Saude Colet 2004; 9(3):795-806.

37. Merhy EE. O ato de governar as tensões constitutivas do agir em saúde como desafio permanente de algumas estratégias gerenciais. Cien Saude Colet 1999; 4(2):305-314.

38. Bossi MLM, Mercado FM. Pesquisa qualitativa de serviços de saúde. Petrópolis: Vozes; 2004.

39. Buss PM. Promoção da saúde e qualidade de vida. Cien Saude Colet 2000; 5(1):163-177.

40. Deleuze G. Post-scriptum sobre as sociedades de controle. In: Deleuze G. Conversações: 1972-1990. Rio de Janeiro: Editora 34; 1992. p. 219-226.

41. Foucault M. Microfísica do poder. $12^{\mathrm{a}}$ ed. Rio de Janeiro: Graal; 1996.

42. Bordenave JED. O que é participação? São Paulo: Brasiliense; 1983.

43. Crevelim MA. Participação da comunidade na equipe de saúde da família: é possível estabelecer um projeto comum entre trabalhadores e usuários? Cien Saude Colet 2005; 10(2):323-331.

44. Gohn MG. Empoderamento e participação da comunidade em políticas sociais. Saúde e Sociedade 2004; 13(2):20-31.

Artigo apresentado em 03/10/2007

Aprovado em 18/07/2008

Versão final apresentada em 27/07/2008 